\title{
Breastfeeding and complementary feeding characteristics in children attend on the primary care in the city of Juchitán de Zaragoza, Oaxaca
}

\begin{abstract}
Introduction: breastfeeding $(\mathrm{BF})$ and complementary feeding $(\mathrm{CF})$ are fundamental practices in the human life process, since it contributes to the growth, maturation and development of the infant; as well as providing short, medium and long term benefits.

Objective: to determine the proportion of breastfeeding in its different forms and to characterize the complementary feeding scheme in children born from 2015 to 2017 who currently attend the primary care in a city in the south of the Mexican Republic.

Material and methods: cross-sectional analytical study, the sample consisted of 150 mothers, who were surveyed for consecutive cases; as long as they met the inclusion criteria.

Results: the practice of BF was high $91.3 \%$, while the exclusive breastfeeding (EBF) was $42 \%$ with an average duration of 1.81 months, $64.1 \%$ of the population studied used milk formula (MF). Women with basic education gave a higher proportion of complementary breastfeeding. The average onset of complementary feeding was 5.9 months, in the scheme of start of CF there is a significant absence of meat; since this food group was introduced on average in the tenth month. Sugar and salt addiction were carried out early 7.57 and 9.69 months respectively.
\end{abstract}

Conclusion: there is a low duration of the EBF and a high use of MF, the CF scheme reflects an important iron deficiency, which can impact on the health of the infant; as well as the early introduction of sugar and salt.

Keywords: breastfeeding, exclusive breastfeeding, complementary feeding, primary care

\author{
Volume 3 Issue 5 - 2019
}

\begin{abstract}
MSP Ramírez Díaz María del Pilar,' MNC Soto Novia Araceli Alejandra, ${ }^{2}$ MSP Luna Hernández Jorge Fernando ${ }^{3}$

Coordinator of projects in Public Health, Nutritional Epidemiology and Epidemiological Surveillance and full-time Research, Professor at Nutrition and Food Research Center of the Degree in Nutrition of the Universidad del Istmo, Mexico ${ }^{2}$ Coordinator of projects in Clinical nutrition and full-time Research, Professor at Nutrition and Food Research Center of the Degree in Nutrition of the Universidad del Istmo, Mexico ${ }^{3}$ Coordinator of projects in Nutrition and Infectious Diseases and full-time Research, Professor at Nutrition and Food Research Center of the Degree in Nutrition of the Universidad del Istmo, Mexico
\end{abstract}

\begin{abstract}
Correspondence: MSP Ramírez Díaz María del Pilar, Coordinator of projects in Public Health, Nutritional Epidemiology and Epidemiological Surveillance and full-time Research, Professor at Nutrition and Food Research Center of the Degree in Nutrition of the Universidad del Istmo (UNISTMO), Juchitán de Zaragoza campus, Oaxaca, Mexico, Tel 229242546I,Email pilar.ramirezdiaz@gmail.com
\end{abstract}

Received: July 23, 2019 | Published: August 17, 2019
Abbreviations: BF, breastfeeding; CF, complementary feeding; EBF, exclusive breastfeeding; MF, milk formula; WHO, world health organization; UNICEF, united nations children's fund

\section{Introduction}

Breastfeeding $(\mathrm{BF})$ is considered the natural means of feeding and nutrition by default for infants, in addition to having physiological benefits for the mother. The evidence indicates that the composition of breast milk is optimal to meet nutritional needs during the first six months and in a complementary manner until 24 months of age. ${ }^{1,2}$ It has been observed that the BF during the first hour of Life after childbirth is crucial to avoid neonatal mortality. ${ }^{3,4}$ It also plays an important role in the infant's debut against the environment and infectious agents, since breast milk has a series of components with immunological function, which allow the protection of the newborn. According to the World Health Organization (WHO), exclusive breastfeeding (EBF) refers to one in which the newborn is only fed with breast milk and no other liquid or solid is introduced except for drops , syrups, vitamins or supplements. ${ }^{6}$ The WHO recommendation for the practice of EBF is to perform it during the first six months of life, although there are still divided opinions and recommendations on the optimal duration of this practice. ${ }^{7}$ After six months of age, the infant's nutritional requirements increase and with it the difficulty of covering them only with breast milk, therefore, the introduction of other food is necessary to favor the correct growth and development of the child. ${ }^{2}$ The transition period between the EBF and the introduction of new foods, including other types of milk, beverages or food is known as complementary feeding (CF). ${ }^{8}$

In the $\mathrm{CF}$, there are guidelines for the introduction of food, since not all are suitable for the child, due to the allergenic potential, the load of solutes or those foods whose nutrients compete for the absorption of others of greater importance such as iron, causing deficiencies and health problems. ${ }^{9}$ For proper CF practice it is essential to know the recommended food scheme for the child's age from six months of age. According to figures from the National Institute of Statistics and Geography (INEGI), in Mexico the percentage of EBF during the first six months of age was estimated at $11 \%$ for $2016,{ }^{10}$ a figure that reflects the progressive abandonment of this practice since in 2006 and 2012 the figures ranged from $22.3 \%$ to $14.5 \%$ respectively, putting a greater proportion of children at nutritional risk. Regarding the correct practice of $\mathrm{CF}$, the figures have been increasing, and of greater relevance is the increase in the introduction of iron-rich foods up to $43.7 \%$ nationwide among children 6 and 11 months of age. ${ }^{11}$ These figures may vary according to geographical area, socioeconomic and socio-cultural factors. This study aims to determine the proportion of breastfeeding and characteristics of complementary feeding in children born from 2015 to 2017 who attend the first level of care in the city of Juchitán de Zaragoza, Oaxaca. 


\section{Material and methods}

Cross-sectional, analytical study conducted on mothers of children born between 2015 and 2017 who currently attend the nine health centers belonging to the health jurisdiction number 2 of the City of Juchitán de Zaragoza, Oaxaca, México. This is located south of the Mexican Republic. The inclusion criteria were: mothers with children between 1 and 3 years old, entitled to the Ministry of Health, who speak Spanish, who accept and sign the informed consent. Lactose intolerance was not considered an exclusion variable for participation in this study. Mothers with lactose intolerant children were allowed to participate in the study, due to the low percentage of this condition in the study population. The instrument designed and used for the investigation "Breastfeeding, complementary feeding and the risk of childhood obesity" was applied, which was modified for a better understanding. ${ }^{12}$ The variables that were considered to be analyzed in this study were: educational level of the mother, number of children, type of breastfeeding, duration of breastfeeding, start of complementary feeding and its characteristics. This research was approved by the head of the health jurisdiction and adheres to the provisions of the Declaration of Helsinki; It is worth mentioning that the participants were given an informed consent, which was signed for their participation.

\section{Statistic analysis}

Descriptive statistics were calculated by means of measures of central tendency such as frequencies and percentages, the analysis of association between the mother's educational level was performed using the $\mathrm{X}^{2}$ test. The information was collected and analyzed by the statistical package SPSS version 24 .

\section{Results}

The sample consisted of 150 women between 15 and 47 years, the average age being 27.9 years. In the following (Table 1) we can see that the predominant sex was male with $52 \%(n=78)$, in terms of educational level the highest proportion was represented by the average level (secondary) $37.3 \%(n=56)$. According to the number of children, $59.3 \%(n=89)$ of the women were primiparous. The following (Table 2) describes breastfeeding practices, we can see that $91.3 \%(n=137)$ of women practiced breastfeeding, and less than half carried out exclusive breastfeeding $42 \%(n=63)$. On the other hand, $86 \%(n=129)$ continued breastfeeding during complementary feeding. While more than half $64.7 \%(n=97)$ gave milk formula to their children. It is important to mention that $2 \%$ (3) of women reported grant milk formula, due to the presence of lactose intolerance of their children. Regarding the average duration of breastfeeding we observe (Table 3 ) that in general its duration was approximately one year, while exclusive breastfeeding did not reach two months (1.86), on the other hand, the duration of Complementary breastfeeding was almost 11 months and the milk formula corresponded to 7.17 months. In relation to the average onset of complementary feeding, it was 5.9 months.

Table 4 compares the proportion of breastfeeding by mother's educational level in which it is shown that there is a higher percentage of women with basic education who provide breastfeeding, exclusive breastfeeding and milk formula (58.1\%, 54\% and 53.1\% respectively), in turn, there is a statistically significant difference in breastfeeding in a complementary manner; being women with basic education who provided in greater proportion compared to women with higher education.

Table 5 shows the characteristics of the complementary feeding, with respect to the beginning of it we found that the highest proportion
(64\%) introduced the first solids at six months or more. The first foods that mothers gave their children were the groups of fruits, vegetables and industrialized foods $(34 \%, 31.3 \%$ and 18.7 respectively). On the other hand, when questioning mothers about the month of food introduction, the meat group was introduced after nine months (9.93); while sugar and added salt were made at 7.57 and 9.69 months, respectively.

Table I Characteristics of the study population

\begin{tabular}{lll}
\hline Variable & $\mathbf{n}$ & $\%$ \\
\hline Children's sex & 78 & 52 \\
Male & 72 & 48 \\
Female & & \\
Mother's level of education & $\mathrm{I}$ & 0.7 \\
No studies & 31 & 20.7 \\
Primary education & 56 & 37.3 \\
Secondary education (Middle) & 40 & 26.7 \\
High school & $\mathrm{I}$ & 0.7 \\
Technical & 21 & 14 \\
University & & \\
Classification of number of births & & \\
First-time births & 89 & 59.3 \\
Multipara & 61 & 40.7 \\
\hline
\end{tabular}

Table 2 Proportion and kind of breastfeeding practiced by mothers

\begin{tabular}{lll}
\hline Variable & $\mathbf{n}$ & $\%$ \\
\hline Breastfeeding & 137 & 91.3 \\
Exclusive breastfeeding & 63 & 42 \\
Complementary breastfeeding & 129 & 86 \\
Infant formula & 97 & 64.7 \\
\hline
\end{tabular}

Table 3 Average duration of breastfeeding and onset of complementary feeding

\begin{tabular}{lllll}
\hline Variable & Average* $^{*}$ & SD & Minimum & Maximum \\
\hline Breastfeeding & 12.58 & 7.97 & 0 & 24 \\
Exclusive breastfeeding & 1.86 & 2.58 & 0 & 8 \\
Complementary breastfeeding & 10.69 & 8.19 & 0 & 24 \\
Milk formula & 7.17 & 8.16 & 0 & 24 \\
Complementary feeding & 5.9 & 2.362 & 1 & 16 \\
\hline
\end{tabular}

*Average duration in months

Table 4 Comparison of proportions of breastfeeding by educational level of the mother

\begin{tabular}{llllll}
\hline Variable & \multicolumn{3}{l}{$\begin{array}{l}\text { Basic } \\
\text { education }\end{array}$} & \multicolumn{3}{l}{$\begin{array}{l}\text { Middle and higher } \\
\text { education }\end{array}$} & $\mathbf{P}^{\mathbf{a}}$ \\
\hline & $\mathbf{n}$ & $\%$ & $\mathbf{n}$ & $\%$ & \\
\hline Breastfeeding & 79 & 58.1 & 57 & 41.9 & 0.809 \\
$\begin{array}{l}\text { Exclusive breastfeeding } \\
\begin{array}{l}\text { Complementary } \\
\text { breastfeeding }\end{array}\end{array}$ & 34 & 54 & 29 & 46 & 0.349 \\
\begin{tabular}{l} 
Milk formula \\
\hline
\end{tabular} & 51 & 61.7 & 49 & 38.3 & $0.042 *$ \\
\hline
\end{tabular}

${ }^{\mathrm{a}} \mathrm{X}^{2}$.

*Significant $p$ value. 
Table 5 Characteristics of complementary feeding

\begin{tabular}{lcc}
\hline Variable & $\mathbf{n}$ & $\%$ \\
\hline Age of onset of complementary feeding & \\
<6 months of age & 54 & 36 \\
$\geq 6$ months of age & 96 & 64 \\
Food group for the start of complementary feeding \\
Fruits & 5 I & 34 \\
Vegetables & 47 & 31.3 \\
Cereals and tubers & 6 & 4 \\
Legumes & 3 & 2 \\
Dairy products & 4 & 2.7 \\
Sea food & 1 & 0.7 \\
Industrialized foods & 28 & 18.7 \\
Combined food* & 10 & 6.7
\end{tabular}

*Foods that contain more than one food group (tlayuda, chiken soups, beef broth, stews).

\section{Discussion}

The $97 \%$ of woman provided their children with breast milk, however, the majority supplemented the infant's diet, more than a half (64.7\%) with milk formula. The multiple components of breast milk provided healthy to health term and preterm infants in the first months of life, favoring their adaptation to post-uterine life with benefits in the development and organs and systems maturation, in addition to the effects positive in acute morbi-mortality, in the development of autoimmune pathologies and in body composition. ${ }^{13,14}$ Breast milk is $90 \%$ water and meets the water needs until the sixth month of life. ${ }^{15}$ Breastfeeding should be maintained during the first 24 months of life, but from the sixth month onwards, the infant's diet should be complemented for proper development. ${ }^{16}$ Since 2017, World Health Organization declared CF should begin at the sixth month of life to prevent child morbidity and mortality, and to ensure child development through nutritional support, gradually increasing the variety of foods and adapting to the requirements and skills of the child, prioritizing the start with adequate sources of zinc and iron for the replenishment of liver reserves. ${ }^{15}$

In this study most mothers began $\mathrm{CF}$ after the sixth month of the infant's life (64\%), CF was preferably started with fruits $(34 \%)$, vegetables $(31.3 \%)$, industrialized foods $(18.7 \%)$ and combined foods $(6.7 \%)$. Although the gastrointestinal tract of the human being reaches, sufficient maturity to receive different foods from breast milk as a complement of diet, the recommendation to maintain EBF until sex month of life is based on the risks of mortality from acute infections considering limited access to clean water and health services worldwide, mainly in developing countries. ${ }^{6}$ In 2012, the monitoring of the Global Strategy in support of the feeding of infants and young children of the United Nations Children's Fund (UNICEF) observed that the practice of EBF is greater among countries in which development pathways, emphasizing that it is necessary to carry out actions that favor the beginning and maintenance of this practice in all countries. ${ }^{17}$ Although it is observed that, on average, the mothers in the sample provided breast milk for more than one year, the duration of the exclusive practice was less than two months, beginning with food supplementation before six months and with milk formula after the seventh month of life; women with secondary and higher education gave significantly less complementary feeding.

Basic education, the establishment of maternity at an early age, obesity in the mother, lower economic income stand out among the social determinants that affect the absence and abandonment of BF. ${ }^{18}$ The largest proportion of women in the sample (37.3\%) have basic education until secondary school; the positive effects, scientifically proven, that exclusive breastfeeding exerts on maternal and child health support the promotion and maintenance of this practice in the first six months of life. ${ }^{18}$ The modest, but consistent benefits of breastfeeding on cognitive development have been widely discussed in the scientific literature due to the difference in the effect observed depending on the environment of the mother; even though women in Europe who for BF and sustain it for a longer time have a significantly better socioeconomic status and educational level favoring a better environment for child development, women in developing countries has the opposite scenario, BF being more prevalent among women in rural areas and with a lower socioeconomic and educational status. ${ }^{19}$

However, in 2015 a meta-analysis that assessed the relationship between intelligence testing and $\mathrm{BF}$ practice in observational studies from 2007 to 2013, showed a modest but significant beneficial effect on IQ in children and adolescents fed with breast milk, however, breastfeeding is considered an appropriate practice for child development, nevertheless the effect of the socioeconomic level of mothers in these studies remained unassessed. ${ }^{20}$ Although the regulations in Mexico promote the start of $\mathrm{CF}$ with meat in the sixth month of life and legumes from the seventh, the women in this study included both groups between the eighth and twelfth months, along with the industrialized foods and added salt. The perception that breast milk production is insufficient to meet the infant's requirements is found globally as a precipitating factor in the incorporation of complementary foods that consequently displace breast milk suction. ${ }^{21}$ However, education and empowerment among women has shown beneficial effects on the onset and maintenance of BF. ${ }^{21}$ Finally, according with the complementary feeding guidelines, allergenic foods should not be included too early or too late to the diet to prevent the development of allergies, in this sample women referred to the consumption of eggs and fish during the first year of life. ${ }^{6}$

\section{Conclusion}

In general, there is a high proportion of breastfeeding; However, its duration is poor mainly in terms of exclusive breastfeeding, since it is well below the WHO recommendations. On the other hand, a considerable proportion of the use of milk formula was observed, this may be due to ignorance of its benefits or bad practice. Regarding complementary breastfeeding, a significant difference was observed between mothers with different educational levels, which indicates the influence of the sociodemographic context in this practice. The start of complementary feeding in its highest proportion adheres to the recommendations; nevertheless, it lacks in its first months in important sources of iron, in addition to adding salt and sugar to the diet.

\section{Acknowledgments}

None.

\section{Conflicts of interest}

The auhtor declares there is no conflict of interest. 


\section{References}

1. Prell C, Koletzko B. Breastfeeding and Complementary Feeding. Dtsch Aerzteblatt Online. 2016;113(25):435-444.

2. Organización Mundial de la salud (OMS). Alimentación del Lactante y del Niño pequeño. 2016. p. 342.

3. Edmond KM, Zandoh C, Quigley MA, et al. Delayed breastfeeding initiation increases risk of neonatal mortality. Pediatrics. 2006;117(3):380386.

4. Mullany LC, Katz J, Li YM, et al. Breast-Feeding Patterns, Time to Initiation, and Mortality Risk among Newborns in Southern Nepal. J Nutr. 2008;138(3):599-603.

5. Cortez J, Makker K, Kraemer DF, et al. Maternal milk feedings reduce sepsis, necrotizing enterocolitis and improve outcomes of premature infants. J Perinatol. 2018;38(1):71-74.

6. Fewtrell M, Bronsky J, Campoy C, et al. Complementary feeding: A position paper by the European Society for Paediatric Gastroenterology, Hepatology, and Nutrition (ESPGHAN) committee on nutrition. J Pediatr Gastroenterol Nutr. 2017;64(1):119-32.

7. Kramer M, Kakuma R. Optimal duration of exclusive breastfeeding (Review). Cochrane Database Syst Rev. Cochrane Database Syst Rev. 2012;(8):1-42.

8. Organización Mundial de la salud (OMS). OMS Alimentación complementaria. J, Muriel. 2013.

9. Thorisdottir AV, Ramel A, Palsson GI, et al. Iron status of one-year-olds and association with breast milk, cow's milk or formula in late infancy. Eur J Nutr. 2013;52(6):1661-1668.

10. Instituto Nacional de Estadística y Geografía (INEGI). Práctica de la lactancia materna en México. 2014. p. 1-14.
11. Encuesta Nacional de Salud y Nutrición 2012. Resultados Nacionales. 2014. p. 1-200.

12. Sandoval Jurado L, Jiménez Báez MV, Olivares Juárez S, et al. Lactancia materna, alimentación complementaria y el riesgo de obesidad infantil. Aten Primaria. 2016;48(9):572-578.

13. Donovan SM. Role of human milk components in gastrointestinal development: Current knowledge and future needs. $J$ Pediatr. 2006;149(5):49-61.

14. Neu J. Gastrointestinal maturation and implications for infant feeding. Early Hum Dev. 2007;83(12):767-75.

15. WHO. Guiding Principles for Feeding Non-Breastfed Children 6-24 Months of Age. Children. 2005.

16. Dewey K. Guiding Principles for Complementary Feeding of the Breastfed child. J Clin Nutr Clin Nutr. 2001;1-40.

17. Cai X, Wardlaw T, Brown DW. Global trends in exclusive breastfeeding. Int Breastfeed J. 2012;7(12):1-5.

18. Lessen R, Kavanagh K. Position of the academy of nutrition and dietetics: promoting and supporting breastfeeding. J Acad Nutr Diet. 2015;115(3):444-449.

19. Jacobson SW, Jacobson JL. Breastfeeding and IQ: Evaluation of the socioenvironmental confounders. Acta Paediatr. 2002;91(3):258-266.

20. Horta BL, Loret De Mola C, Victora CG. Breastfeeding and intelligence: A systematic review and meta-analysis. Acta Paediatr Int J Paediatr. 2015;104(467):14-19.

21. Dieterich CM, Felice JP, O’Sullivan E, et al. Breastfeeding and Health Outcomes for the Mother-Infant Dyad. Pediatr Clin North Am. 2013;60(1):31-48. 